\title{
COMUNICAÇÃO E PERCEPÇÕES SOBRE SAÚDE: O OLHAR DOS USUÁRIOS NA ESTRATÉGIA SAÚDE DA FAMÍLIA
}

\author{
COMMUNICATION AND PERCEPTIONS OF HEALTH: THE POINT OF \\ VIEW OF PATIENTS IN THE FAMILY HEALTH STRATEGY
}

\section{Carolina Lopes de Lima Reigada}

Médica de Família e Comunidade, preceptora da residência médica em Medicina de Família e Comunidade da Universidade do Estado do Rio de Janeiro

E-mail: carol_reigada@yahoo.com. br

\section{Valéria Ferreira Romano}

Doutora em Saúde Coletiva pelo Instituto de Medicina Social da Universidade do Estado do Rio de Janeiro, Professora Adjunta da Faculdade de Medicina da Universidade Federal do Rio de Janeiro.

E-mail: valromano@uol.com.br

\section{Resumo}

A comunicação, em sua essência polissêmica, aciona sentidos diversos para usuários e profissionais de saúde, especialmente nas concepções que envolvem saúde, cuidado e processo de trabalho. O objetivo deste artigo é o de analisar a percepção de usuários de uma favela do município do Rio de Janeiro sobre o conceito de saúde e processo de trabalho ofertado pela equipe da Estratégia Saúde da Família localizada na mesma. Trata-se de um estudo qualitativo de abordagem sócioantropológica que utilizou entrevistas semiestruturadas com os usuários adscritos. Percebeuse que a disparidade entre as concepções abordadas movimentaram implicações diretas no processo de trabalho da equipe, gerando entre a população e os profissionais de saúde menos potência e mais desencontro.

Palavras-chave: Estratégia Saúde da Família; Comunicação; Saúde; Trabalho. 


\section{Abstract}

Communication, in a polysemic aim, has engaged several meanings to users and healthcare professionals, especially in issues that involves health, care and work process. The objective of this article is to analyze the perception of slum dwellers patients at Rio de Janeiro on the concept of health and work process offered by the Family Health Strategy team responsible by them. This is a socio-anthropological approach qualitative study which applied semi-structured interviews in the patients. It was noticed that the difference between the concepts addressed had direct implications at the work process, culminating in less power and more disagreement between the population and healthcare professionals.

Keywords: Family Health Strategy; Communication; Health; Work.

\section{Introdução}

Qualquer comunicação entre sujeitos implica em relação, em troca, em escuta de sentidos diversos sobre algum tema. No entanto, se entendermos o conceito de comunicação considerando um modelo informacional onde o emissor transmite uma mensagem que chega diretamente ao receptor - exceto se algum ruído se interpor entre eles - poderemos perceber este modelo de comunicação com um direcionamento quase que linear: emissormensagem-receptor. Tal ideia tradicional sobre a comunicação, transposta para a saúde, sugere a crença de que a prática comunicativa se limita à transferência de informações a uma população que nada sabe de relevante sobre assuntos que dizem respeito à sua saúde e à sua vida. Tal postura ao silenciar o direito de voz e expressão do outro, termina por produzir um trabalho em saúde centrado nos profissionais, numa concepção de saúde pouco ampliada.

No entanto, em contrapartida, se pensarmos a comunicação como uma rede de processos onde dimensões afetivas, cognitivas, econômicas e políticas simultaneamente perpassam sentidos conectantes entre emissores e receptores, poderíamos vê-la como polissêmica, ${ }^{1} \mathrm{com}$ conflitos de interesses na disputa por relações de poder. ${ }^{2}$ Vale esclarecer aqui que, do ponto de vista da linguística, ou melhor, da área de estudo científico da Linguagem, entendemos, que todo signo é ideológico, ou seja, quando evocamos uma palavra, ela vem repleta de significados, que representam na verdade fragmentos materiais de uma dada realidade. ${ }^{1}$ Então, se todo signo é ideológico, se toda palavra produz sentidos ideológicos, quando nos comunicamos com o outro estamos na verdade trocando elementos que representam contextos concretos sobre a realidade que acreditamos existir, que defendemos existir. Tal ideia coloca em questão o cuidado que devemos ter diante de qualquer comunicação com as pessoas, principalmente, na comunidade, em atividades de educação em saúde. Nada do que é dito está isento de uma ideologia que se materializa. A cultura, enquanto promotora de valores e significados, serve como força de dominação em uma sociedade dividida em classes, como a nossa. ${ }^{2}$ Ou seja, a classe dominante se utiliza da palavra, do signo, da ideologia, para impor sua cultura, dando-lhe assim um valor incontestável. Acentuando as diferenças entre as classes, e escamoteando conflitos de interesse na disputa por relações de poder, a classe dominante desvaloriza a cultura popular e suas formas de comunicação e expressão.

Desta maneira, neste artigo, aceitamos como premissa que diante de qualquer comunicação entre pessoas há 
necessariamente a presença da diversidade e da diferença.

Assim, abordamos a comunicação entre usuários moradores de uma favela e profissionais de saúde de uma Unidade Básica com Estratégia Saúde da Família e nos defrontamos com abismos comunicacionais, que geraram dissonâncias nas relações e no processo de trabalho. Mas também promoveram uma chamada à criatividade na busca por uma comunicação democrática.

Este artigo, fruto das reflexões de uma então Residente de Medicina de Família e Comunidade da Universidade Federal do Rio de Janeiro, aborda a polissemia do conceito de saúde e seus reflexos na percepção sobre o processo de trabalho. Reflete ainda uma preocupação com o encontro (desencontro?) entre sujeitos, no desejo de superar abismos entre comunicação, saúde e trabalho.

Portanto, a grande pergunta que nos fizemos foi: Significados sobre saúde e processo de trabalho possuem alguma interface entre usuários e profissionais de saúde? Que implicações isto imprime ao mundo do trabalho em saúde?

\section{Método}

Trata-se de uma pesquisa qualitativa com abordagem sócio-antropológica, ${ }^{3}$ utilizando entrevistas semiestruturadas com usuários cadastrados de uma equipe da Estratégia Saúde da Família do município do Rio de Janeiro. As entrevistas foram realizadas em uma sala reservada para tal fim, gravadas com autorização prévia do entrevistado, perfazendo um total de 200 horas de gravação. Foram realizadas seis entrevistas, consideradas suficientes pelo critério de saturação, quando a repetitividade das respostas justifica a interrupção da pesquisa. ${ }^{3}$
Os critérios de inclusão utilizados foram: possuir mais de 18 anos e ter sido atendido por membros da equipe de saúde pesquisada. A análise de dados foi realizada segundo a Análise de Conteúdo, conforme Minayo, ${ }^{3}$ na vertente da Análise Temática.

$O$ projeto de pesquisa foi avaliado pelo Comitê de Ética em Pesquisa do Hospital Universitário Clementino Fraga Filho, da Universidade Federal do Rio de Janeiro, tendo sido aprovado sem ressalvas no dia 26/10/12, sob protocolo número CAAE: 20922313.9.0000.5257.

\section{Resultados e Discussão}

Saúde: definição majoritariamente biológica

Na narrativa dos usuários o conceito de saúde apareceu com um entendimento majoritariamente biológico, além de intimamente conectado à presença do médico.

Todos os entrevistados relacionaram saúde a bem-estar físico (como o contrário de "doença"), definindo-a como a ausência de sintomas biológicos (principalmente dor) ou como controle de doenças crônicas.

Saúde, nesse caso, não seria construída na comunidade, na família ou pelo próprio indivíduo, como uma forma de autocuidado, como uma postura de corresponsabilidade, mas sim interligada ao consumo da medicina tecnológica. Além disso, ressaltaram conexão entre saúde e capacidade de trabalhar e/ou desempenhar atividades cotidianas, demonstrando um sentido prático e utilitário na percepção sobre saúde.

"Saúde é nunca ficar doente, sem dor nenhuma, nada. Doente fica péssimo pra tudo, não faz nada. Pessoa doente não é ninguém" (Entrevistado E). 
"Saúde é a melhor coisa que tem. Quando eu fiquei doente, senti na pele o que é, agora estou melhor. Não sou saudável porque tenho essa doença, mas eu me sinto bem agora. Saúde vem em primeiro lugar porque sem saúde não se consegue trabalhar, não se consegue sobreviver. Eu tenho saúde porque eu consigo fazer as coisas, eu consigo trabalhar" (Entrevistado D).

"Saúde é tudo na vida da gente. 0 que somos nós sem saúde? Não fazemos nada." (Entrevista F).

Alguns estudiosos ${ }^{4,5}$ abordaram essa concepção utilitária da saúde ao ressaltar que, em nossa sociedade capitalista, saúde e doença são pensadas como fatores de produção, onde o sistema de saúde é organizado para manter o indivíduo produtivo, normatizado e normalizado. Entrevistando população de baixa renda em favelas do Rio de Janeiro, Minayo ${ }^{4}$ chegou a uma conclusão semelhante: a concepção de que a doença se traduz em incapacidade para trabalhar e realizar afazeres cotidianos. Ressaltou que essa associação não é natural e sim socialmente construída de acordo com a ideologia capitalista e, para a classe trabalhadora, tem valor estipulado sob a forma de salário. Concluiu que "Saúde, doença e trabalho constituem, portanto, uma interdependente e cotidiana relação, que pode ser traduzida pela própria concepção de vida."4

Vale aqui um parênteses sobre a utilização do termo favela, assumido como um termo melhor adequado do que comunidade, já que mantém o sentido de heterogeneidades sociais presentes.

Mas, apesar de serem moradores de uma favela com alta vulnerabilidade, expostos à violência, problemas de saneamento e habitação, não surgiu nas entrevistas qualquer associação entre saúde e lazer, modos de vida ou cultura da paz; reforçando uma ideia biologicista, prevalente no discurso e na prática da medicina, que impõe sua cultura dominante. ${ }^{2}$

Estes resultados vão de encontro à discussão sobre a ampliação do conceito de saúde, que permeia os estudos em Saúde Pública pelo menos desde a década de 60 , quando debates amplos em todo o mundo começaram a realçar a determinação social da saúde, ampliando o cuidado para além da orientação centrada exclusivamente no controle da enfermidade. ${ }^{6,7}$ Com a Conferência de Alma Ata (1978), esses esforços foram consolidados e, em todo mundo, o debate se fortaleceu com as Conferências Internacionais de Saúde e suas Declarações, como a Carta de Ottawa (1986). Seu texto apontava para a influência dos aspectos sociais sobre a saúde, caracterizando-a como o "processo de capacitação da comunidade para atuar na melhoria de sua qualidade de vida e saúde, incluindo uma maior participação no controle desse processo." ${ }^{\prime 7}$ No Brasil, com o movimento de Reforma Sanitária, esse conceito foi incluso na abordagem integral do usuário. Mais tarde, a Integralidade foi valorizada como um dos princípios do SUS. ${ }^{8}$

A representação de saúde registrada por nosso estudo - estar saudável é estar isento de patologias ou apto para o aspecto laboral da vida - é coerente com a lógica de trabalho centrada em consultas médicas rápidas e frequentes, adotada nos últimos anos na Estratégia Saúde da Família. Dessa forma, pode-se entender a grande demanda para marcação de consultas e atendimentos queixa-conduta, além da baixa adesão a grupos terapêuticos, atividades em sala de espera para promoção de saúde, como observado no cotidiano da unidade de saúde pesquisada. Tais fatos, expressam signos ideológicos ${ }^{1}$ que costuram uma realidade que valoriza o corpo enquanto simples produção, enquanto instrumento de produção para o trabalho para as classes dominantes. 
A saúde somente é alcançada através do médico

Como exposto acima, a concepção de saúde que emerge das entrevistas é biologicista, reducionista e medicalocêntrica, em acordo com diversos autores que abordam a medicalização da vida e a legitimação do saber técnico biológico e científico como hegemônico na sociedade ocidental contemporânea. 5,10,11 Uma óbvia conclusão endossa a crença na prescrição de comportamentos tecnicamente justificados como única forma possível de alcançar bem-estar. ${ }^{10,11}$ As manifestações populares, "leigas", de cuidado à saúde são desacreditadas em prol do saber científico. ${ }^{9}$ Comportamentos "não-educados" são considerados insuficientes, insalubres, inadequados - até de risco, ${ }^{9}$ o que afasta uma condição de diálogo mútuo, afetando a comunicação entre usuários e profissionais de saúde.

A medicina interpõe sua lógica sobre as formas de viver fazendo com que os sujeitos percam sua singularidade e autonomia, reforçando os sentidos da Biopolítica. ${ }^{5}$

Outra questão é que uma volumosa procura por consultas médicas ambulatoriais tem gerado grande tensão entre a capacidade de oferta dos profissionais e as demandas da população, entre uma equipe que frequentemente funciona em seu limite máximo de atendimento e sujeitos que creem que a única maneira de alcançar saúde é através do encontro com o médico - não com seus pares, não com outros profissionais, não com sua família ou comunidade.

\section{0 atendimento médico deve ser imediato, não programado}

Ao serem perguntados sobre o que os leva a procurar atendimento em saúde, todos responderam que vão ao médico quando sentem alguma dor ou têm algum sintoma que precise de remédio. Apesar de todos os entrevistados terem acesso a consultas agendadas (como pré-natal, puericultura e condições crônicas), apenas dois disseram que procuram a Unidade Básica de Saúde quando estão agendados, descartando qualquer demanda de procura por uma medicina preventiva, além de justificar o grande absenteísmo nas consultas previamente agendadas.

"Quando eu passo mal. Dificilmente você vai a um serviço se não está sentindo nada ou se não tem um compromisso" (Entrevistado C).

"Vou só se tiver que fazer um exame ou atacada da bronquite. Fora disso, não" (Entrevista E).

Victor Valla ${ }^{13}$ afirma que profissionais e população não vivem a mesma experiência de doença. Cita como exemplo o modo de trabalho dos sanitaristas, baseado na previsão, em olhar para o futuro e agir no presente de forma a prevenir agravos que possam surgir. Entretanto, as classes populares vivem baseadas na provisão. As dificuldades de sobrevivência fazem com que seu foco seja o presente, não o planejamento para o futuro. As classes populares teriam, então, uma idéia de acumulação e imediatismo. ${ }^{13}$

A preocupação com o acesso, a importância da longitudinalidade $e$ do tempo de espera

Quando perguntados sobre a existência de diferenças no estilo de atendimento entre uma Unidade Básica de Saúde e uma UPA (Unidade de Pronto Atendimento), os entrevistados em geral relataram não perceber qualquer diferença entre ambas. No entanto, ficou claro o quanto valorizam a relação médico-usuário e a longitudinalidade. 
"Acho que é a mesma coisa. Sou bem atendida nos dois locais, não posso reclamar." (Entrevistada A).

"A UPA é emergência, aqui não é, mas aqui já me conhecem, eu conheço e sou bem atendido." (Entrevistada D).

Outra questão destacada foi o tempo de espera para o atendimento à demanda espontânea:

"A diferença é que na UPA eu fui atendida muito rápido, talvez porque eu estava passando muito mal. Aqui demora um pouco mais, porque a pessoa não está tão mal e tem outro procedimento. É para atender todo mundo, tem que esperar"(Entrevistada C).

“Não vejo diferença nenhuma. Lá na UPA, chegando muito ruim, a gente entra direto, aqui a gente espera. Só essa a diferença. Mais nada" (Entrevistada E).

A grande quantidade de queixas da população, porém sem proposta de soluções

Seria interessante, para nossa análise, diferenciar "queixa" de "demanda". A queixa seria uma reclamação do usuário como catarse, sem que haja expectativa de melhora quanto a ela. Já sobre a demanda, há uma perspectiva de melhora, de mudança, de transformação.

Parece que entre os usuários pesquisados há uma cultura de insatisfação com os serviços públicos, que se expressa no modo como lidam com os profissionais de saúde. Estariam mais preocupados com queixas do que demandas? Possivelmente sim, principalmente se compreendermos que na base desta insatisfação há uma longa história de descaso com essa parcela da população, fruto de importantes desigualdades econômicas, sociais e ambientais ${ }^{15}$.
Assim, os usuários não participam com propostas de mudanças ou melhorias para o serviço de saúde que utilizam. Comunicação e Saúde aumentam espaços no abismo em que se encontram.

\section{Considerações Finais}

Sea comunicação entre os profissionais de saúde e os usuários não fizer sentido para ambos, restarão tensões a serem compartilhadas. As consequências podem ser antevistas: profissionais e usuários insatisfeitos, desgastados e desmotivados pelos atritos diários e sentimento de baixa eficácia de suas ações e expectativas. Mas, seria possível promovermos aproximações de sentidos ideológicos opostos em uma sociedade dividida em classes? De que lugar falam os médicos, a medicina, os sujeitos da favela, a população? Que disputas estão colocadas neste cenário?

A pesquisa revelou, com certa obviedade, que a visão dos sujeitos sobre saúde difere dos conceitos utilizados pela Saúde da Família e pela Saúde Coletiva, fazendo supor que novos olhares poderiam ser visitados na premissa de que as necessidades de saúde da população sejam priorizadas. Novos signos poderiam ser tocados.

Apesar do esforço e preocupação dos profissionais de saúde em ofertar cuidado, o que prevalece é um atendimento médicocentrado que, naturalizado pelos usuários, imobiliza iniciativas de autocuidado e participação comunitária, secundarizando, ou mesmo desconsiderando uma medicina que se propõe a ter na integralidade um sentido.

Não basta querer mudar a sociedade, é fundamental saber mudar buscando a igualdade de oportunidade e liberdade para todos e todas. ${ }^{14,16}$ Mas devemos estar atentos para não acabarmos utilizando as 


\section{Artigo Original}

mesmas ferramentas: querermos libertar dominando. ${ }^{16}$

Finalizando, na polissemia da saúde, assumimos a comunicação em rede como fundamental, insistindo na aposta de que promover encontros entre a equipe de saúde e os usuários só será possível se profundamente aceitarmos ambiguidades, diferenças e dissensos como caminhos. Estamos prontos para tal?

\section{Referências}

1. Bakthin M. Marxismo e Filosofia da Linguagem. São Paulo: Hucitec; 1992.

2. Bordieu P. O Poder Simbólico. 9a ed. Rio de Janeiro: Editora; 2006.

3. Minayo MCS, Gomes SFDR. Pesquisa Social. Teoria, método e criatividade. Rio de Janeiro: Editora Vozes; 2012.

4. Minayo MCS. Saúde: concepções e políticas públicas. In: Amâncio Filho A, Moreira MCGB, organizadores. Saúde, trabalho e formação profissional. Rio de Janeiro: FIOCRUZ; 1997: 138

5. Foucault M. O Nascimento da Biopolítica. São Paulo: Martins Fontes; 2008.

${ }^{6}$. Ferreira JR, Buss PM. Atenção Primária e Promoção da Saúde. In: Ministério da Saúde. As cartas de promoção à saúde. Brasília: Editora MS; 2002: 7-17.

7. Heidmann ITSB, Almeida MCP, Boehs AE, Wosny AM, Monticelli M. Promoção à saúde: trajetória histórica de suas concepções. Texto Contexto Enferm, 2006; 15(2): 352-8.

8. Mattos RA. A integralidade na prática. Cad. Saúde Pública 2004; 20(5):1411-1416.

9. Ayres, JRCM, Meyer, DEE, Mello, DF, Valadão, MM. Você aprende. A gente ensina? Interrogando relações entre educação e saúde desde a perspectiva da vulnerabilidade. Cadernos de Saúde Pública 2006; 22(6): 1335-1342.

10. Tesser CD. Medicalização Social e Atenção à Saúde no SUS. São Paulo: Hucitec; 2010.

11. Santos BS. Um Discurso sobre as Ciências. 7a. ed. São Paulo: ed. Cortez; 2010.

12. Merhy EE. A Cartografia do Trabalho Vivo. 3a ed. São Paulo: Hucitec; 2002.

13. Valla VV. Sobre participação popular: uma questão de perspectiva. Cadernos de Saúde Pública, 1998; 14 (Sup.2): 7-18.

14. Freire P. Pedagogia da Autonomia: saberes necessários à prática educativa. 36a. ed. São Paulo: Paz e Terra; 2007.

${ }^{15}$. Baeninger R, organizador. População e Cidades subsidios para o planejamento e para as políticas sociais. Campinas: Núcleo de Estudos de População - Nepo/ UNICAMP; Brasília: UNFPA; 2010.

16. Ceccim RB. Pacientes impacientes: Paulo Freire. In: Secretaria de Gestão Estratégica e Participativa (BR). Caderno de educação popular e saúde. Brasília: MS; 2007: 32-45. 